\title{
Evaluation of the Acute Management of Tetraplegia: Conservative versus Surgical Treatment
}

\author{
Conal B. Wilmot, M.D. ${ }^{1}$ and Karyl M. Hall, Ed.D. ${ }^{2}$ \\ ${ }^{1}$ Chairman, Department of Physical Medicine and Rehabilitation, Santa Clara \\ Valley Medical Centre, 751 So. Bascom Avenue, San fose, California 95128, \\ U.S.A. Director and ${ }^{2}$ Co-Director, Northern California Regional Spinal Injury \\ System, Institute for Medical Research, 2260 Clove Drive, San Fose, California \\ 95128, U.S.A.
}

\section{Summary}

A retrospective study of 106 tetraplegic patients admitted consecutively to the Santa Clara Valley Medical Center (SCVMC) between August, 1981 and September, 1983 was conducted. The average age was 28; and $20(19 \%)$ were female. The majority sustained their spinal cord injury in a motor vehicle accident $(65 \%)$ or in a diving accident $(19 \%)$. Forty-nine percent (52/106) of these patients had acute surgical intervention, and $63^{\circ}{ }_{o}(33 / 52)$ of these patients had this prior to admission to SCVMC. The majority (35/52) had posterior fusion alone. Twelve patients had an anterior fusion (11 at other hospitals) and four a laminectomy alone (three carried out at other hospitals).

The length of rehabilitation stay was 133 days for those having surgery, and 119 days for non-surgical cases; statistically a non-significant difference. When acute medical/surgical hospitalisation and rehabilitation days were combined, those having surgery had a significantly longer stay (197 versus 153 days), but only when surgery was done other than at SCVMC. Complications occurred in 50/106 $(47 \%)$ of the patients: $50 \%$ who had surgery and $44 \%$ who were treated conservatively. The most commonest complication was respiratory $(43 \%)$, including $20 \%$ who had pneumonia. Complications were no greater in those patients who underwent posterior fusion than in those who had no spinal surgery. However, other types of surgery carried a higher risk of complications by approximately $20 \%$. Anterior fusions and laminectomies, performed almost totally at other institutions (15/17), had a higher rate of complications.

Key words: Tetraplegia; Surgery; Outcome; Medical complications; Cost.

\section{Introduction}

The acute management of cervical spinal cord injury remains a controversial issue. Sir Ludwig Guttmann (1973) advocated that maintaining the patient in bed in traction would reduce a significant number of bony injuries and allow the spine 
to fuse. Bedbrook (1979) suggested that surgery is utilised much more often than necessary. His review of the literature led him to believe that the possible benefits of internal fixation do not justify the risks and complications of such operations. In contrast, Bohlman (1979) found that closed or open reduction followed by posterior fusion for subluxations or dislocations and anterior decompression and fusion for vertebral compression fractures offered the best chance for recovery of function and effective stabilisation. Whitehill and Schmidt (1983) concluded in their study of 22 quadriplegics that posterior fusion was safe and effective when compared to other treatments for cervical instability.

The purpose of this study was to determine the outcome of the acute cervical cord injured after being given a specific treatment regimen, including acute surgical intervention in defined cases.

\section{Materials}

A retrospective review of medical records for 2 years (between $9 / 1 / 81$ and $8 / 1 / 83$ ) was completed and 106 tetraplegic spinal cord injured patients were identified as consecutive new admissions to the SCVMC rehabilitation program. The average age was 28 years, and $81 \%$ were male. The largest number sustained injuries in an automobile accident $\left(46^{\circ}{ }_{0}\right)$, followed by motorcycle and diving accidents $(19 \%$ each) and falls $\left(9^{\circ}{ }_{0}\right)$. Average days from injury to admission for those who had surgery at SCVMC was 11.5 days, and for those with surgey elsewhere, 60 days. For those who had no surgery, mean days was 31 . Mean days spent in rehabilitation for the total group was 125. Fifty-three percent of tetraplegic admissions had complete lesions. Two patients died whilst undergoing rehabilitation.

Data on medical complications in-hospital, relevant to acute management, were collected. Type of surgery and the Frankel classification at admission and discharge from the rehabilitation unit were also obtained from the medical records.

\section{Methods}

At SCVMC, the rationale for the treatment provided is to

1. preserve or improve neurological function.

2. reduce the misalignment, meaning dislocation, fracture dislocation or subluxation.

3. stabilise the neck.

4. mobilise the patient as soon as possible.

Virtually all acute admissions arrive at the unit with skull traction GardnerWells tongs, or Halo rings. If the dislocation/fracture dislocation is reduced, and the patient's general condition is stable, the patient is provided with the following choices:

1. Halo Ace jacket in those with neurologically complete lesions,

2. Halo Lite cast with fixation on the pelvis in patients with neurologically incomplete lesions, or

3. traction in bed for as long as is deemed necessary. This latter (3) is the only option for someone of unsuitable build (obese) or who is unstable medically.

If the dislocation/fracture dislocation fails to become reduced by traction, and if the patient has a complete neurological lesion with a unilateral locked facet, an 
attempt is made to manipulate and reduce the dislocation under anaesthesia and relaxation. This very rarely occurs. If reduction still fails, the unilateral locked facet will be accepted and the patient will be mobilised as previously, except in two very rare instances where there is severe root pain, or a lopsided neurological lesion (e.g., C4 right, C6 left). These might be surgically reduced to relieve pain or to save nerve roots. In patients with bilateral locked facets and evidence of instability, surgical reduction and posterior fusion will be carried out.

If the dislocation/fracture dislocation fails to reduce on traction, and if the patient has an incomplete neurological lesion, he/she will be surgically reduced and fused posteriorly, whether there are unilateral or bilateral locked facets.

Laminectomy in closed neck injuries is rarely done and only for the following reasons:

1. When an incomplete neurological lesion is deteriorating and a myelographic block is demonstrated posteriorly (if the block is demonstrated anteriorly, the surgical approach should be anterior);

2. When there is a complete lesion that is deteriorating ('rising'), involving at least two levels with demonstrated myelographic block.

If laminectomy is performed, it is always accompanied by fusion. The patient is then mobilised in the appropriate device.

\section{Results}

Forty-nine percent $(52 / 106)$ of tetraplegics had acute surgical intervention $\left(18^{\circ} \mathrm{o}\right.$ at SCVMC). Of those having surgery, $67 \%$ had posterior reduction and fusion alone (Table 1).

Table 1 Acute Surgical Intervention in Quadriplegics

\begin{tabular}{lcccc}
\hline Type of Surgery & SCVMC & Elsewhere & Total & ${ }^{0}(\mathrm{~N} / 106)$ \\
\hline Posterior Fusion (PF) & 17 & 18 & 35 & 33 \\
Anterior Fusion (AF) & $1^{\star}$ & 7 & 8 & $7 \cdot 5$ \\
PF and AF & 0 & 2 & 2 & $1 \cdot 8$ \\
PF and Laminectomy & 0 & 1 & 1 & .9 \\
AF and Laminectomy & 0 & 2 & 2 & 1.8 \\
Laminectomy Alone & 19 & 33 & 4 & 3.7 \\
Subtotal (surgeries) & & & 52 & 49 \\
No surgery & & & 54 & 51 \\
Total & & & 106 & 100 \\
\hline
\end{tabular}

* fragmented vertebrae ${ }^{\star \star}$ deteriorating lesion

For those having surgery, rehabilitation stay was an average of 133 days $(N=49$, S.D. $=59)$, and for those with no surgery, 119 days $(N=53$, S.D. $=61)$. The difference in days was not statistically significant $(t=1.203)$. Median lengths of stay were 120 and 112 days respectively. However, when days of acute medical/surgical hospitalisation and rehabilitation stay were combined, a significant difference in days was found between those having spinal surgery of any kind outside of SCVMC and those not having surgery (Table 2). That is, those having surgery outside SCVMC were hospitalised for a significantly greater number of days. 
Table 2 Days of Hospitalization from Injury to Rehabilitation Discharge

\begin{tabular}{rcccccc}
\hline & $\begin{array}{c}\text { No } \\
\text { Surgery }\end{array}$ & $\begin{array}{c}\text { Surgery } \\
\text { at SCVMC }\end{array}$ & $\begin{array}{c}\text { Surgery } \\
\text { Elsewhere }\end{array}$ & $\mathrm{t}$ & $\mathrm{p}$ (2-tailed) \\
\cline { 3 - 7 } & $151 \cdot 5$ & $144 \cdot 1$ & $194 \cdot 6$ & $1 \& 2:-0 \cdot 347$ & \\
$\mathrm{SD}$ & $81 \cdot 2$ & $58 \cdot 6$ & $102 \cdot 0$ & $1 \& 3:-2 \cdot 157$ & .05 \\
$\mathrm{~N}^{\star}$ & 52 & 17 & 33 & $2 \& 3:-1 \cdot 882$ & \\
Median & $130 \cdot 5$ & 146 & 166 & & \\
Range & $27-404$ & $22-252$ & $83-588$ & & \\
\hline
\end{tabular}

* a few cases had missing data

Table 3 Medical Complications in Quadriplegics: Acute Surgical Intervention versus No Surgery

\begin{tabular}{ccc}
\hline Type of Surgery & $\begin{array}{c}\text { Number of Patients } \\
\text { With Complications }\end{array}$ & Percent \\
\hline Posterior Fusion Only & $15 / 35$ & $42 \cdot 8$ \\
All other surgeries & $11 / 17$ & $64 \cdot 7$ \\
No Surgery & $24 / 54$ & $4 \cdot 4$ \\
\hline
\end{tabular}

$\star 15$ of the 17 surgeries were done at other hospitals

Table 4 Medical Complications in Tetraplegics: Types of Complications ${ }^{\star}$

\begin{tabular}{|c|c|c|c|c|}
\hline \multirow[b]{2}{*}{ Complication } & \multicolumn{3}{|c|}{ No Surgery } & \multirow{2}{*}{$\begin{array}{l}\text { Surgery } \\
{ }_{0} \mathrm{~N} / 52\end{array}$} \\
\hline & $\mathbf{N}$ & ${ }_{0}^{o} \mathrm{~N} / 54$ & $\mathbf{N}$ & \\
\hline Pneumonia & 9 & $16 \cdot 7$ & 7 & $13 \cdot 5$ \\
\hline Atelectasis & 7 & $13 \cdot 0$ & 12 & $23 \cdot 1$ \\
\hline Decubiti & 7 & $13 \cdot 0$ & 15 & $28 \cdot 8$ \\
\hline Thrombophlebitis & 8 & $14 \cdot 8$ & 0 & 0 \\
\hline Pulmonary Embolism & 2 & $3 \cdot 7$ & 1 & 1.9 \\
\hline Post-Op Wound Infection & 0 & 0 & 2 & $3 \cdot 8$ \\
\hline Spontaneous Pneumotho- & & & & \\
\hline $\operatorname{rax}$ & 2 & $3 \cdot 7$ & 0 & 0 \\
\hline GI Hemorrhage & 1 & 1.9 & 0 & 0 \\
\hline Cardiopulmonary Arrest & 2 & $3 \cdot 7$ & 4 & $7 \cdot 7$ \\
\hline Hemothorax & 1 & 1.9 & 0 & 0 \\
\hline Respiratory Distress & 2 & $3 \cdot 7$ & 0 & 0 \\
\hline Pulmonary Congestion & 1 & 1.9 & 3 & $5 \cdot 8$ \\
\hline
\end{tabular}

* Several patients had more than one complication

There was no significant difference in length of stay between those having surgery at SCVMC and those who did not have surgery.

Forty-four percent of those having no surgery had medical complications within the period of rehabilitation stay. Fifty percent $(26 / 52)$ of patients who had surgery were reported to have medical complications, possible but not definitely due to the surgery (Table 3). Thirty-seven percent of these patients with complications had surgery at SCVMC and $58 \%$ elsewhere. The seven SCVMC surgery patients with complications had no multiple complications whereas nine of the 19 patients having surgery at other hospitals had multiple complications. Three of the four laminectomy only cases reported complications.

Thrombophlebitis and respiratory problems were the most common complications in non-surgical cases ( $15^{\circ}$ o each; 8/54 in each category). Pneumonia and 
Table 5 Change in Frankel Classification Between Rehabilitation Admission and Discharge

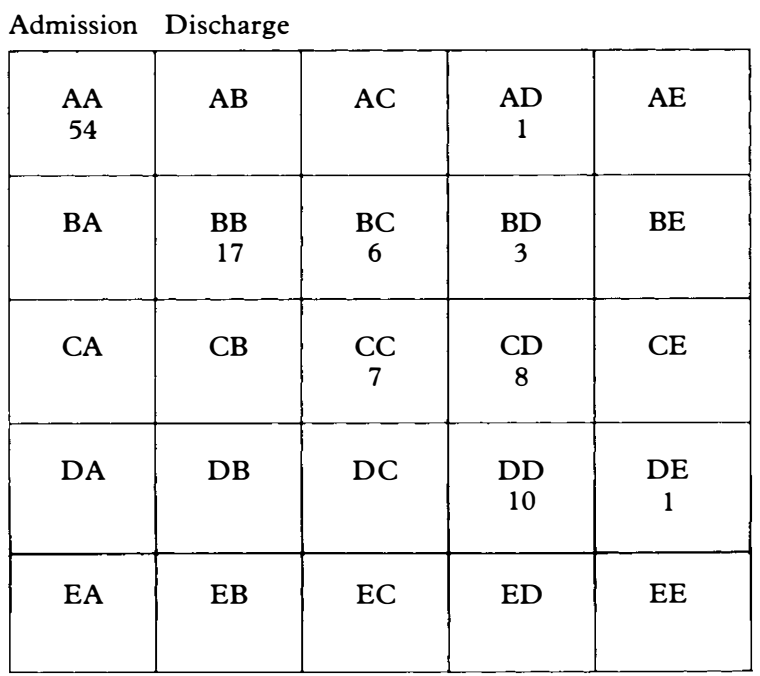

decubiti each occurred in $11 \%$ of cases. In the patients who had spinal surgery pneumonia was the most common complication $(29 \% ; 15 / 52)$, followed by respiratory problems $(27 \%)$ and decubiti $(23 \%)$ (Table 4 ).

Eighteen of the 106 tetraplegics improved in Frankel Classification between admission and discharge from rehabilitation. Eighty-eight did not change and none worsened. Of the 18 who improved, 9 had no surgery, 6 had a posterior fusion, and 3 had other forms of surgery (Table 5).

\section{Discussion}

Almost half of the 106 tetraplegic patients in the study had acute surgical intervention, $19(18 \%)$ at SCVMC and $33(31 \%)$ elsewhere. The majority had a posterior fusion.

The total numbers of hospital days was similar between those who did not have surgery and those who had surgery at SCVMC. Those having surgery elsewhere, however, had significantly longer hospital stays than those not having surgery, a median difference of 27 days. This translates into a significant cost differential. It appears that the major difference in surgical approach between SCVMC and other centres is that elsewhere there is greater use of the operation of anterior fusion and laminectomy. At SCVMC surgery of any kind on tetraplegics is only performed as per stated protocol, and is almost without exception a posterior reduction and fusion.

Complications were no greater in those patients who underwent posterior fusion than in those who did not have surgery. However, other types of surgery carried a higher risk of complications by approximately $20 \%$. The type of surgery and/or the complication rate may have adversely affected length of stay, because SCVMC had fewer patients with complications, and those who had complications had only one whereas multiple complications occurred more often at other hospitals.

It is interesting to note that $18 \%$ of patients improved in Frankel Class between 
rehabilitation admission and discharge. This improvement cannot be attributed to surgical intervention per se, as half of the improved patients had not had surgery.

\section{Acknowledgements}

The treatment protocol as outlined was developed primarily through interaction with Richard D. Hamilton, M.D., Chief of Neurosurgery, Glenn G. Reynolds, M.D., Physiatrist, and Steven Fountain, M.D., Chief of Orthopedic Surgery. Grateful appreciation is extended to these individuals for their invaluable contributions to the program.

This research was supported in part by the Northern California Regional Spinal Injury System, Grant No. G008435010, Project No. 128EH40013, from the Rehabilitation Services Administration, U.S. Department of Education, Washington, D.C.

\section{Résumé}

On a employé la contention externe pour traiter les fractures de la tige fémorale chez neuf souffrants à blessure de la moelle épinière (SCI). Un souffrant est mort de causes sans rapport pendant le traitement de la fracture. Des huit souffrants qui restaient, sept ont guéri leur fracture. Deux complications - un drainage superficiel de la voie de clavette et une comminution de la fracture-se sont produites chez les neuf souffrants. Ni l'une ni l'autre de ces complications n'a adversement influé sur le résultat final du souffrant.

Chez les souffrants à blessure aiguë de la moelle épinière, on devrait considérer la contention externe pour le traitement des fractures fermées de la tige fémorale avec comminution marquée, ainsi que pour les fractures ouvertes de la tige fémorale avec contamination ou perte de tissu mou significative. Chez le souffrant chronique à SCI, la contention externe peut accroître le niveau d'indépendance et de mobilité du souffrant pendant la guérison, et elle peut permettre un retour plus rapide au niveau fonctionnel du souffrant d'avant la fracture.

\section{Zusammenfassung}

Man hat äussere Fixation gebraucht, um Femurschaftfrakturen bei neun rückenmarkverletzten (SCI) Patienten zu behandeln. Ein Patient ist von unbezogenen Ursachen während der Behandlung gestorben. Von den verbleibenden acht Patienten haben sieben ihre Fraktur geheilt. Zwei Komplikationen, und zwar eine oberflächliche Zapfenwegdränage und ein Fraktursplitterbruch, sind bei den neun Patienten vorgekommen. Keine von diesen Komplikationen hat das Endergebnis des Patienten nachteilig beeinflüsst.

Bei Patienten mit akuter Rückenmarkverletzung sollte man äussere Fixation für die Behandlung von geschlossenen Femurschaftfrakturen mit betrachtlichem Splitterbruch, wie auch für offene Femurschaftfrakturen mit bedeutender Verunreinigung oder Weichgewebenverlust berücksichtigen. Bei dem chronischen SCI-Patienten kann die äussere Fixation von einer Femurschaftfraktur das Niveau der Unabhängigkeit und Beweglichkeit während des Heilprozesses erhöhen, und sie kann auch eine schnellere Rückkehr zum vor der Fraktur geltenden Funktionsniveau erlauben.

\section{References}

BEDBROOK G M 1979 Spinal injuries with tetraplegia and paraplegia. Journal of Bone and Joint Surgery, 61-B, 267-274.

BoHLMAN HH 1979 Acute fractures and dislocations of the cervical spine. Journal of Bone and Joint Surgery, 61-A, 1119-1141.

Guttmann L 1973 Spinal Cord Injuries: Comprehensive Management and Research. Blackwell Scientific Publications: London.

WhITEHILL R \& SCHMIDT R 1983 The posterior inter-spinous fusion in the treatment of quadriplegia. Spine, 8, 733-740. 